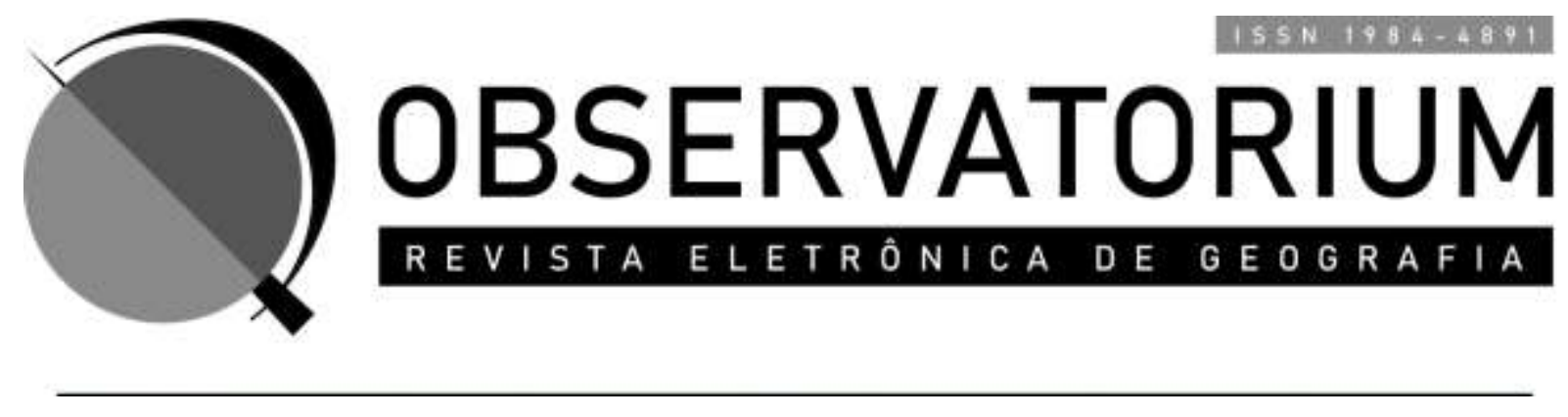

\title{
AS UNIVERSIDADES E SUA IMPORTÂNCIA NA FORMAÇÃO TERRITORIAL BRASILEIRA: O CASO DE MINAS GERAIS. ${ }^{1}$
}

UNIVERSITIES AND THEIR IMPORTANCE IN BRAZILIAN TERRITORIAL FORMATION: THE

CASE OF MINAS GERAIS

Rita de Cassia Martins de Souza Anselmo ${ }^{2}$

\section{RESUMO}

As Instituições de Ensino Superior, sobretudo as universidades federais e estaduais, ocupam um lugar central na estruturação do estado em Minas Gerais. Nesse sentido, este trabalho traz à luz algumas reflexões iniciais acerca do papel que as universidades desempenham na modernização do território mineiro.

PALAVRAS-CHAVES: Universidades Públicas; Modernização; Minas Gerais

\begin{abstract}
Higher Education Institutions, especially public universities, occupy a central place in the structuring of Minas Gerais. In this sense, this work brings to light some initial reflections on the role that universities play in the modernization of the territory of Minas Gerais.
\end{abstract}

KEYWORDS: Public Universities; Modernization; Minas Gerais

\footnotetext{
${ }^{1}$ Este trabalho diz respeito à pesquisa desenvolvida com o apoio da FAPEMIG sob o título: "A geografia produzida em Minas Gerais: os cursos de Geografia na UFMG, UFJF, UNIMONTES, UNIFAL e UFU e seu papel na estruturação do território mineiro". Processo: APQ-01851-15

2 Docente de Graduação e Pós-Graduação do Instituto de Geografia da Universidade Federal de Uberlândia-UFU. E-mail: ritacmsou@gmail.com
} 


\section{INTRODUÇÃO}

As universidades e sua reestruturação acabaram se tornando um dos temas mais debatidos contemporaneamente mundo afora. A globalização e seus efeitos positivos e perversos não poderiam deixar de atingir essas instituições seja por condições estruturais como sua privatização ou os novos sentidos que a elas são demandados. Como centros produtores de conhecimento e de tecnologias, as universidades carregam ainda mais a responsabilidade por produzirem novas significações simbólico-culturais e, concomitantemente, a crítica e a autocrítica de seus resultados e efeitos.

Entretanto, há de se considerar que pela força que essa instituição assumiu no conjunto social, os questionamentos sobre sua importância e sua atuação têm sido permanentes desde seu aparecimento. Seu envolvimento com a produção científica a coloca num patamar de forte relevância no sentido da oferta de soluções para os problemas cotidianos e na formulação de estratégias futuras para a humanidade. Para além disso, o foco da atenção se volta sobre as mesmas pelo espírito crítico que as acompanha. Nesse sentido, o livre pensar as torna num espaço de debate e embate do conhecimento e dos próprios rumos que a sociedade pode tomar.

No caso do Brasil, as universidades tiveram a sua criação bastante retardada por questões que somente a compreensão da formação social brasileira pode responder. Segundo Gomes (2002):

As primeiras universidades fora da Europa se fizeram na América espanhola. Criada em 1538, a Universidade de São Domingos é historicamente a primeira universidade das Américas. Depois vieram as de San Marcos, no Peru (1551), México (1553), Bogotá (1662), Cuzco (1692), Havana (1728) e Santiago (1738). As primeiras universidades norte-americanas, Harvard, Yale e Filadélfia, surgiram respectivamente em 1636, 1701 e 1755 .

A primeira universidade no Brasil foi implantada em 1920 com a denominação de Universidade do Rio de Janeiro (mais tarde Universidade do Brasil). Deu-se pela reunião de antigas escolas superiores instaladas anteriormente da mesma forma que a Universidade de Minas Gerais, instalada em Belo Horizonte, em 1927. Ambas acompanhavam os ideais da modernidade tão desejada ou "falada" desde a Proclamação da República (1889). De maneira especial deve-se destacar a criação da Universidade de São Paulo em 1934, ou seja, num momento de extrema relevância para a história nacional, dado que esse é o marco da transformação do país de uma condição 
exclusivamente agrário-exportadora para a de urbano-industrial, conforme Francisco de Oliveira (2003). A partir do modelo da USP implantaram-se as universidades no país num processo de interiorização da ocupação e paralelamente de modernização do interior, como aqui se pretende demonstrar.

Mediante o exposto cabe ressaltar que este trabalho tem como objetivo apresentar uma parte das reflexões que foram feitas durante o desenvolvimento de uma pesquisa sobre as universidades em Minas Gerais, no intuito de compreender a lógica espacial de suas instalações sobre o território mineiro. Mais especificamente, procurou-se compreender a contribuição dada pelos cursos de Geografia encampados pelas mesmas em determinados campi. Duas questões centrais acompanharam o seu desenvolvimento quais sejam: se a instalação das universidades não é aleatória, em Minas Gerais qual sentido prevaleceu na escolha dos lugares; segundo, dado que, por temário, a Geografia preocupa-se com o reconhecimento do espaço, qual foi contribuição regional que os cursos dessa frente científica trouxeram.

A instalação dessas universidades públicas, federais e estaduais, bem como de outras instituições como os Institutos Federais-IFs e CEFETs, em verdade acompanharam a proposta da Reestruturação Econômica de Minas Gerais encampada no pós Guerra pelo governo mineiro. Evidentemente, essa condição se refletiu e se reflete até hoje na estruturação do estado e apresenta um interesse particular a esta pesquisa que transcende o aspecto particular do funcionamento interno dessas instituições estendendo-se para preocupação com o papel que as mesmas desempenharam na formação territorial do estado mineiro e, por corolário, sobre a formação nacional de forma geral. A composição em "mosaico regional" do estado de Minas Gerais - conforme Dulcci (1999) propôs utilizando-se da formulação original de Wirth (1982) - serviu de guia para o entendimento da distribuição de suas diversas universidades públicas que acompanhou o processo de instalação das vias de transporte e da rede de energia elétrica. Juntos, esses aparatos técnicos, fixos conforme Santos (2002), desempenharam papel central na modernização do território mineiro levando não somente os equipamentos, mas essas universidades atuaram no sentido de fluxos imateriais (ainda conforme a conceituação de Santos, 1996).

É sobre esses fluxos que reside a maior importância dessas instituições produtoras de uma energia ou melhor seria, sinergia, que assegurou o sucesso do processo de modernização. A concordância com o projeto territorial brasileiro apresentou-se como uma característica particular conforme a pesquisa foi se 
desenvolvendo. A necessidade da compreensão da formação territorial brasileira no sentido dos princípios e dos ideários que a acompanharam e acompanham acabou se tornando uma questão central no desenvolvimento deste trabalho na medida que se colocou como evidência que essas universidades fazem parte de um processo maior de desenvolvimento do estado de Minas Gerais, mas além disso, de asseguramento da unidade administrativa. Com isso se quer dizer que as diferentes partes do Mosaico regional se coadunaram no ideal da construção do estado e têm nos equipamentos instalados e no "conhecimento" produzido a sua sustentação.

Nesse sentido este texto concentra-se na apresentação da importância da universidade para o projeto territorial brasileiro e para o de Minas Gerais, particularmente.

\section{AS UNIVERSIDADES PÚBLICAS E O PROJETO TERRITORIAL BRASILEIRO}

O caso da inserção brasileira na modernidade pode ser compreendido a partir dos primeiros passos dados no país no sentido do desenvolvimento científico, em que os diversos Institutos Históricos e Geográficos e a atração de viajantes naturalistas, ainda no século XIX, constituem-se em exemplos. O Manifesto Republicano de 1870 é considerado um desses marcos da modernização brasileira. Nesse documento enfatizava-se a necessidade urgente da abolição da escravidão e da instauração da República no Brasil, sendo essas mudanças compreendidas pela intelectualidade e, por corolário, pela "elite" à época, como indispensáveis para garantir a entrada do país na modernidade.

Após a proclamação da República, a questão voltou a ser obrigatoriamente colocada. Segundo alguns historiadores, os positivistas da revolução de 1889 receavam duas coisas: de um lado, a proliferação dos ideais liberais da Revolução Francesa e, de outro, a disseminação do ensino católico. Nessa toada, o projeto da primeira universidade demoraria ainda duas décadas para se esboçar. (GOMES, 2006)

Segundo Machado (1995), o final do século XIX e o início do XX configurou-se como o momento chave da modernização no Brasil tendo assumido a partir daí um sentido mais complexo que o da mera modernização técnica, mas de mudança de 
pensamento, de ideários e abrindo-se para uma nova fase do país em uma nova posição no contexto internacional.

No decorrer dos sessenta anos que separam a promulgação da "Lei do Ventre Livre" (1872) da Revolução de 1930, momento que os historiadores costumam apontar como marco da ascensão de um "projeto de modernização" no Brasil, completou-se a transição do trabalho escravo para o trabalho livre, as diferenças econômicas e sociais entre as regiões brasileiras se aguçaram, a monarquia foi sucedida pela República, e o principal mercado para os produtos brasileiros se deslocou da Europa para os Estados Unidos. Examinadas em retrospectiva, a última década do século XIX e as três primeiras do século XX podem ser vistas como uma época da redefinição da identidade nacional. (Machado, 1995, p. 309)

A temática gerada em torno das universidades foi também discutida nesse momento e se desdobrou nas Conferências Nacionais de Educação, nos respectivos anos de 1927, 1928 e 1929, revelando os anseios que estavam presentes pelo menos entre alguns setores das classes dominantes do período.

A urbanização brasileira do início do século XX, as escolhas e as apostas na industrialização nos anos de 1930-40, o desenvolvimento tecnológico acelerado dos anos JK (1956-60), desdobrados no desenvolvimento pensado e conduzido desde os governos militares têm muito a dizer a respeito da ciência e de como ela foi se compondo, assumindo certos discursos, incorporando determinados conceitos e certas formas de fazer, atrelados às necessidades da organização social desejada e, por consequência, da organização do território de modo a atender essas demandas.

Nesse conjunto de iniciativas deve-se sempre remeter ao projeto de sociedade ou de país e, no mínimo, há de se retomar o projeto de integração econômica, proposto por Getúlio Vargas, que se baseava num audacioso processo de modernização abrangendo as estruturas produtivas em todo o território nacional, juntamente com o desenvolvimento dos centros industriais, o que garantiria o progresso técnico e econômico do Brasil.

A necessidade de industrializar e modernizar o território galgou caminhos pelo interior do país, ampliando as fronteiras para além do litoral ou das zonas concentradas de modernização, ou seja, a capital Rio de Janeiro e São Paulo. Visavase alcançar a integração econômica do interior às áreas centrais em termos políticos (com a representação no Rio de Janeiro, capital à época) e em termos econômicos (já que São Paulo se industrializava desde o final do XIX e com a I Guerra), revestindo-se de um conteúdo político ideológico, voltado para a ocupação econômica e demográfica, 
como um esforço de "valorização do interior" (a chamada "Marcha para Oeste" de Vargas).

Os anos do pós-Segunda Guerra foram marcados também por numerosas políticas de interiorização da modernização no país. Bons exemplos disso são: o planejamento estratégico, a construção da capital Brasília no centro do país, a reformulação da primeira regionalização implementada no governo Vargas, a construção de várias estradas federais e estaduais acompanhando os planos viários etc.

Particularmente essas iniciativas de interiorização foram acompanhadas do ideal de disseminar pelo país as instituições de ensino superior e técnico. Dezenas de Faculdades Isoladas ou Escolas Isoladas foram fundadas nesses anos, e, a partir dessas, as universidades começaram a ser instaladas no interior. A criação dos cursos universitários, portanto, rompeu as fronteiras para além de São Paulo e Rio de Janeiro e, além deles também os Institutos Federais de Ensino e os CEFETs.

Necessário dizer sob quê aspectos se pode deslindar essa expansão das instituições de ensino superior e técnico para o interior. De imediato há de se considerar, sem dúvida, a intencionalidade do capital acerca da "qualificação do trabalho" e/ou da mão de obra de um lado e, de outro, o que pode ser chamado de qualificação dos lugares no sentido do atendimento das demandas socioeconômicas de forma local e específica. No entanto, as ações via Estado (seja em nível federal ou estadual, mas também municipal, o que talvez seja o mais interessante aqui) que promovem ou viabilizam essas demandas, podem ser entendidas enquanto projetos territoriais estatais e, evidentemente, de suas classes dirigentes. Nesse sentido, é importante ter em conta que um tal projeto como se quer tratar aqui, não está circunscrito a um período restrito de tempo e nem a uma de suas escalas exclusivamente, mas acompanha um ideário que está para além das necessidades momentâneas ou de escalas específicas, ou seja, enquanto projeto de Estado, essas demandas subjazem permanentemente ao processo da formação social, ganhando contornos e tonalidades à medida que o processo geral da formação socioespacial admite e/ou requer.

Para o caso do Brasil devemos lembrar da proposição da profa. Bertha Becker (1993) que já insistia na ideia do projeto geopolítico brasileiro enquanto uma ascensão do país à condição de potência regional na economia mundo, o que remete à necessidade de esforço no entendimento do projeto territorial brasileiro. Por trás das políticas de interiorização em nível nacional há um esforço contínuo no sentido de dar 
ao país uma condição geoestratégica na Divisão Internacional do Trabalho que está para além de um momento ou de uma escala restrita.

Esse projeto como aqui tratado, não engessa de maneira alguma, as iniciativas que são postas em cada tempo. Ou seja, uma coisa são as necessidades postas na década de 1930, outras são as necessidades e possibilidades do pós guerra, bem como de outros momentos que se queira considerar, inclusive o período mais recente em que a interiorização responde a novos arranjos produtivos trazidos pela globalização em que claramente podemos enquadrar as reestruturações do ensino superior no Brasil.

Interessante notar que, para além das especificidades de cada um desses momentos em que houve alguma interiorização, no caso, das Instituições de Ensino Superior-IES, sempre esteve presente nos discursos, ou mais especificamente, nas normas (conforme Santos, 2002) que regeram essas expansões, dois fundamentos primordiais: o de promover o desenvolvimento ; e, o de reduzir as desigualdades regionais. A cada período histórico específico, essas duas preocupações vêm acompanhadas de denominações adequadas a cada momento, mas que enfim mantêm sempre um fundamento principal que é o da unidade da nação e do território brasileiro. Com todos os desafios e contradições que isso implica. Embora se tenha que admitir, juntamente com outros estudiosos da temática, que seja realmente difícil fazer uma associação direta dessas políticas de interiorização das IES com políticas explícitas de desenvolvimento regional ou de integração nacional, uma vez que não há um conjunto de normas que direcionem diretamente nesse sentido, pode-se afirmar o caráter mediato dessa interação que só se pode apreender pelos discursos veiculados ao longo do processo histórico pelos grupos dominantes que assim defendem o projeto territorial brasileiro.

\section{O CASO DE MINAS GERAIS E SUAS INSTITUIÇÕES DE ENSINO SUPERIOR PÚBLICAS}

A partir dessas reflexões então é possível pensar o caso específico da instalação das universidades e de outras IES no estado de Minas Gerais enquanto parte inerente do processo de interiorização da modernização no país.

A necessidade de ordenamento do território como meio mais eficaz para a “imposição” da modernidade aparece implícito nos desejos da elite mineira, desde o 
fim do século XIX, na busca pelo fim da estagnação econômica vivenciada no estado desde o final do século XVIII.

Para se compreender esse movimento há de se resgatar as iniciativas dos Planos de Recuperação Econômica de Minas implementados sobretudo após os anos de 1930, que se tornaram decisivos para a implementação de uma série de medidas e da instalação de objetos técnicos decisivos na direção da modernização do território, mas também num sentido mais amplo e fluido como o cultural. Entre esses objetos técnicos há de se considerar as instituições de ensino como decisivas para o bom funcionamento das estratégias de recuperação econômica. Dessa forma, a instalação de grandes empreendimentos hidrelétricos, de rodovias integradoras do estado, aliadas aos incentivos à industrialização não teriam viabilidade sem uma grande transformação do pensamento e dos hábitos da população de Minas Gerais. Este último aspecto exige tratamento aprofundado e extenso à guisa de sua apreensão.

Atualmente Minas Gerais possui 11 universidades públicas federais espalhadas por todo o estado (Mapa 1), sendo que algumas destas, como a Universidade Federal de Minas Gerais - UFMG, a Universidade Federal de Alfenas - UNIFAL, a Universidade Federal de Uberlândia - UFU, a Universidade Federal de Juiz de Fora UFJF, a Universidade Federal de Viçosa - UFV, entre outras, destacam-se nacionalmente enquanto instituições referência na promoção das atividades de pesquisa, ensino e extensão, ganhando destaque no ordenamento e na modernização das regiões mineiras. 


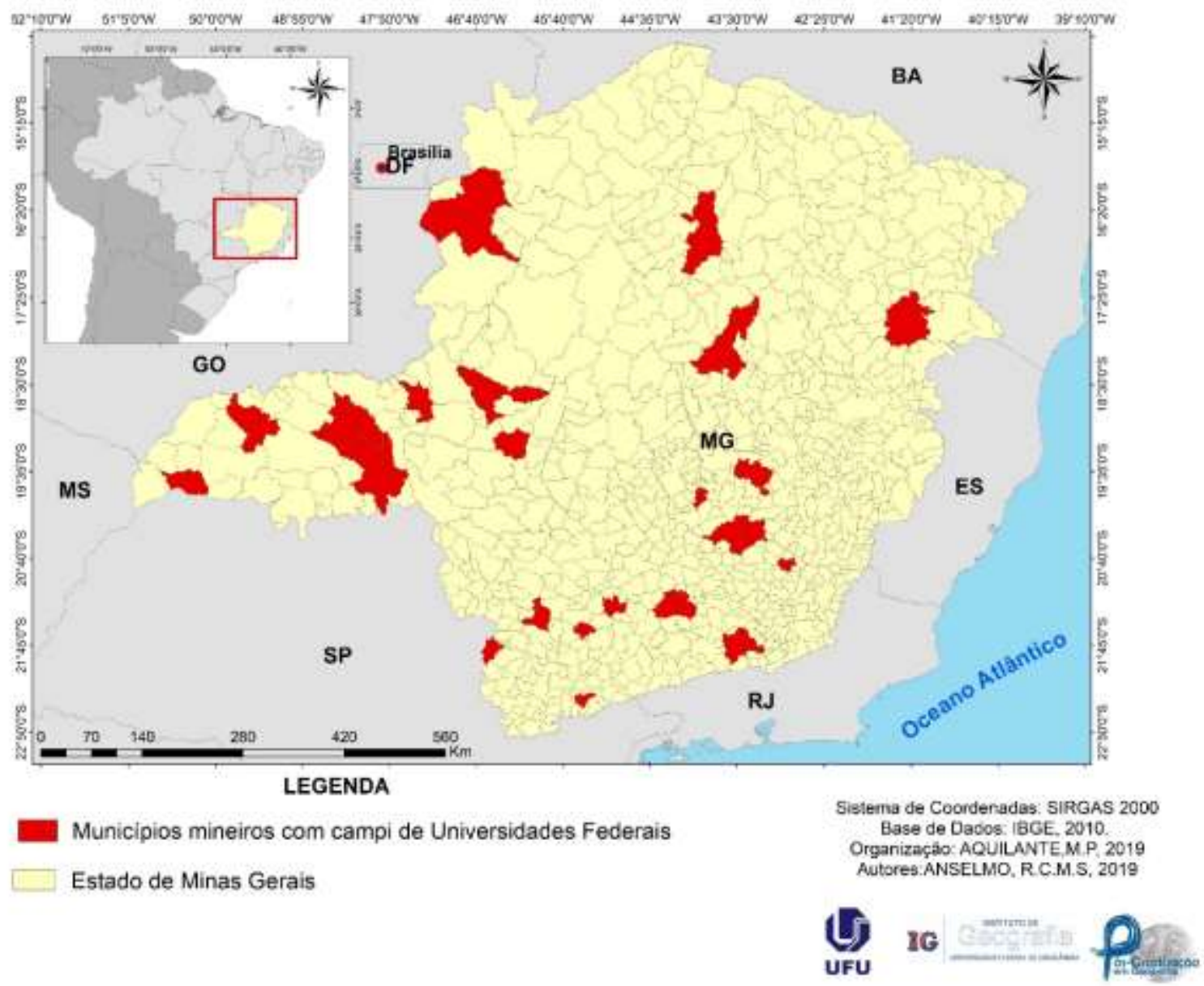

Mapa 1 - Municípios de Minas Gerais-Brasil com campi de Universidades Federais. Fonte: ANSELMO, R. C. M. S., 2019.

Deve-se destacar ainda que Minas Gerais apresenta uma situação peculiar em relação aos demais estados brasileiros, pois é a unidade da federação que mais possui Instituições de Ensino Superior públicas no país: um total de 68 (Mapa 2). 


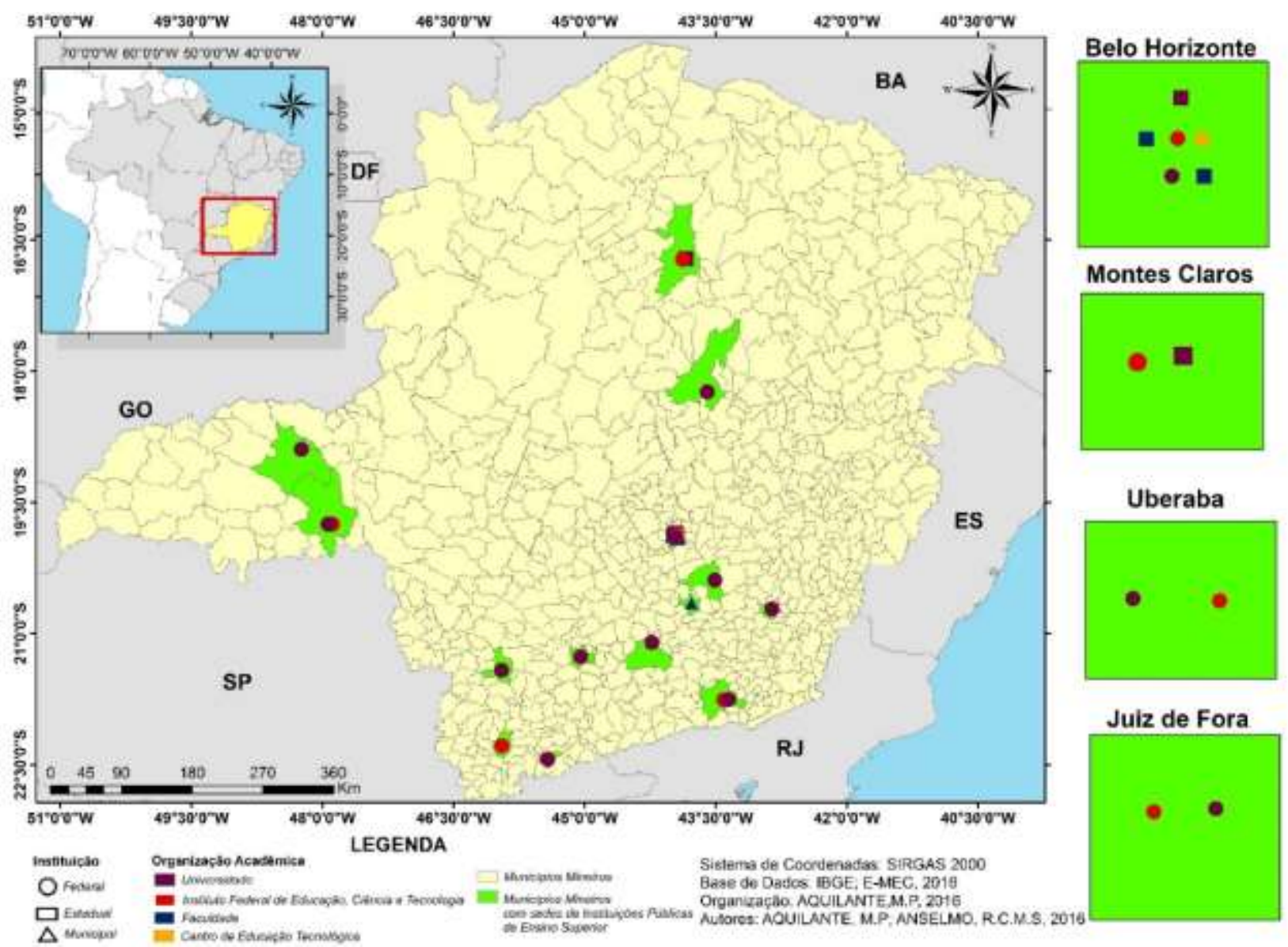

Mapa 2 - Instituições Públicas de Ensino Superior em Minas Gerais-Brasil. Fonte: ANSELMO, R. C. M. S., 2019.

Sendo que desse total, além das 11 (onze) universidades federais espalhadas por 27 cidades de todo o Estado, 02 (duas) são universidades estaduais, espalhadas por 16 cidades (Mapa 3), segundo o site do Ministério da Educação (2011). 


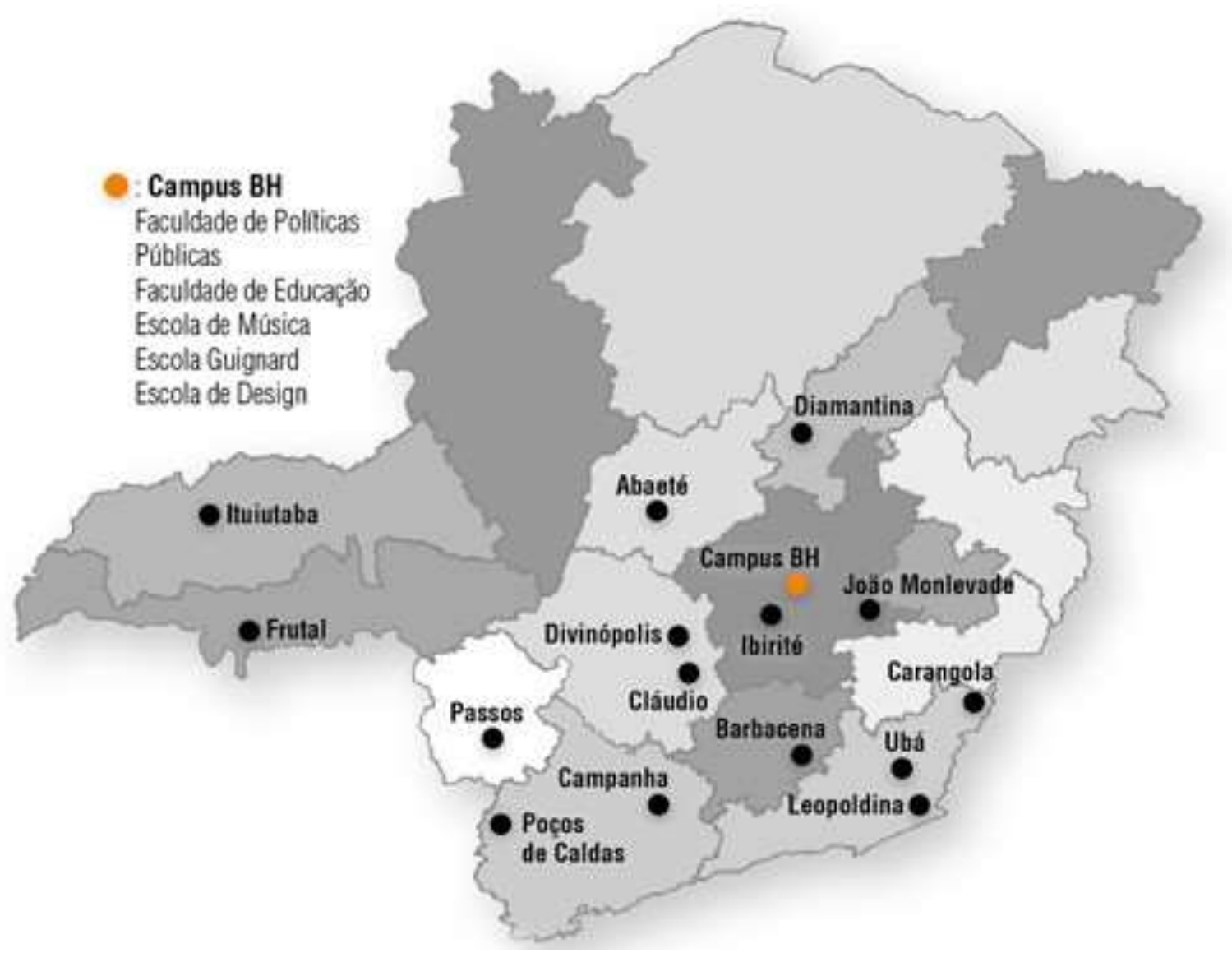

Mapa 3 - Universidades Estaduais de Minas Gerais-Brasil. Fonte: MEC.

Ainda é interessante destacar os 5 (cinco) Institutos Federais-IFs, distribuídos por 61 cidades. E o CEFET com campi distribuídos em 9 municípios (1909-Belo Horizonte; 1987-Leopoldina; 1992:Araxá; 1994:Divinópolis; 2006:Timóteo; 2006:Varginha; 2007:Nepomuceno; 2010:Curvelo; 2012:Contagem).

Compreendendo a universidade pública enquanto objeto técnico, nota-se que a disposição desse grande número de IES garante a produção de pesquisas financiadas pelo poder público, que, para além do conhecimento amplo gerado, tem direta relação com a formação dos quadros de profissionais necessários regional e nacionalmente, e, além disso, possibilitam o (re)conhecimento científico das diversas "regiões" do estado mineiro, através das pesquisas produzidas.

É possível perceber que onde se fixam essas instituições há um aumento considerável pela demanda técnica e científica, uma vez que a chegada da universidade bem como de outras IES se reflete no crescimento populacional dos municípios, no aumento da urbanização, na chegada de outras empresas e serviços que complementam a modernização do lugar. 
A universidade pública gera não somente a força de trabalho qualificada para suprir as demandas geradas por essas empresas, mas também produz as pesquisas responsáveis por "desvendar" e potencializar a dinâmica territorial. Além desses objetivos, as universidades cumprem um papel primordial de formação de quadros de intelectuais entre os quais encontram-se os professores. De forma geral, estes são os condutores do pensamento moderno nas bases do sistema, ou seja, na transformação das ideias dos lugares onde atuam. São os preparadores da recepção das ideias modernas entre os jovens. E isso tem grande importância para esta pesquisa na medida que se trata de áreas, que no processo de interiorização, passam a receber o ideário moderno. Há uma forte conversão dos pensamentos tradicionais locais em uma universalização via ensino dos conteúdos modernos obrigatórios das escolas formais, assunto que exige ainda, um aprofundamento nesta pesquisa.

Assim ocorreu principalmente com as cidades do interior do estado de Minas Gerais, originalmente fundadas distantes da modernidade proveniente do litoral. Cidades como Uberlândia, Juiz de Fora, Montes Claros, Alfenas, Viçosa passam a ser polos difusores da modernidade, principalmente após a chegada da universidade às respectivas cidades: Universidade Federal de Juiz de Fora (1960), Universidade de Montes Claros (1964), Universidade Federal de Viçosa (1969) Universidade Federal de Uberlândia (1969).

Enfim, há uma forte ligação entre a chegada das universidades públicas, cujas informações são relevantes para a base do desenvolvimento e a chegada da modernidade ao interior de Minas Gerais. Em geral, a universidade mineira é alocada em cidades estratégicas distribuídas pelos cinco cantos do estado, onde a elite local tem interesse e poder para trazer um grande empreendimento federal ou estadual.

Para os efeitos da pesquisa aqui parcialmente apresentada, os cinco cantos da unidade administrativa mineira mencionados correspondem ao chamado "Mosaico Mineiro”. A proposição, encontrada em Wirth (1982), Dulci (1999) e outros estudiosos, é um constructo que se delineia não somente pela evolução econômica, mas guarda em si uma complexa rede de interações políticas e culturais imprescindíveis para a sua compreensão, assunto para outra oportunidade de publicação. 


\section{ALGUMAS CONSIDERAÇÕES FINAIS}

Conclui-se, a partir do exposto que, para compreendermos o papel que a universidade pública assume na construção do espaço mineiro é necessário entendê-la tanto enquanto um objeto técnico infra-estrutural, tanto enquanto agente de difusão de certas necessidades homogeneizadoras e universais, geradas pela própria alocação deste objeto técnico no espaço.

Esses pontos de vista evidentemente podem ser questionados à luz de outras perspectivas como por exemplo a de que por trás desses pontos que podem ser entendidos como positivos da chegada e da expansão das universidades para o interior do Brasil, há o efeito perverso da concentração dos aparatos técnicos em determinados lugares em função do poder econômico e político dos agentes locais. Isso é verdade de certa forma. A instalação das instituições de ensino, no caso de Minas Gerais, em geral, é instigadora da atração de outros equipamentos sobre o território e sem dúvida, são usados como uma política territorial justamente para produzir esse efeito. Muitas das cidades que receberam tanto as universidades como os institutos federais promoveram um processo de urbanização importante, sendo a renda desses municípios poderosamente estimulado por esse processo.

É preciso considerar que o efeito dessa urbanização e da transformação dessas áreas menos envolvidas com o processo produtivo se deu e se dá ao longo de um processo que veio se instalando desde o início do século e mais acentuadamente desde 1960 conforme já dito. E o que se observa é que os efeitos da modernização "imposta" acabou trazendo efeitos sobre o atendimento médico, o grau de escolarização, a atração de uma nova dinâmica cultural etc que transformaram e continuam transformando os lugares e adaptando-os sem dúvida para a recepção da lógica da produção dominante. Ou seja, os lugares passam a fazer parte da lógica produtiva dominante reproduzindo, como não poderia ser diferente, também as mazelas do próprio sistema visto que ao concentrar riqueza o processo também traz a pobreza, ou que o que poderia ser traduzido como a impossibilidade de desfrutar da riqueza que todos produzem. 


\section{REFERÊNCIAS}

BECKER, B. Brasil. uma nova potência regional na economia-mundo. Rio de Janeiro: Bertrand Brasil, 1993.

DULCI, Otávio Soares. Política e recuperação econômica em Minas Gerais. Belo Horizonte: UFMG, 1999.

GOMES, E. O Mandarin. História da infância da Unicamp. Campinas: Ed. Unicamp, 2006.

MACHADO, L.O. Origens do pensamento geográfico no Brasil. Espaços vazios e a ideia da ordem. In: CASTRO, I.E.; GOMES, P.P.C.; CORRÊA, R.L. Geografia. Conceitos e temas. Rio de Janeiro: Bertrand Brasil, 1995.

MEC. Ministério da Educação. Conheça a evolução da educação brasileira. $<$ http://portal.mec.gov.br/component/content/article/33771-institucional/83591conheca-a-evolucao-da-educacao-brasileira $>$. Acesso em: 10/02/2021.

OLIVEIRA, F. Crítica à Razão Dualista: o Ornitorrinco. São Paulo: Ed. Boitempo, 2003.

SANTOS, M. A natureza do espaço. Técnica e tempo. Razão e emoção. São Paulo: Hucitec, 2002.

WIRTH, J. D. O fiel da balança: Minas Gerais na federação brasileira, 1889- 1930. Rio de Janeiro: Paz e Terra, 1978. 